\title{
Safety Improvements on Wood Chippers Currently in Use: A Study on Feasibility in the Italian Context
}

\author{
Giorgia Bagagiolo $^{1}$ (D), Vincenzo Laurendi ${ }^{2}$ and Eugenio Cavallo ${ }^{1, *}$ \\ 1 Institute for Agricultural and Earth Moving Machines (IMAMOTER), National Research Council of \\ Italy (CNR), Strada delle Cacce 73, 10135 Torino, Italy; g.bagagiolo@ima.to.cnr.it \\ 2 National Institute for Insurance Against Accidents at Work (INAIL), Via di Fontana Candida 1, \\ Monte Porzio Catone, 00078 Roma, Italy; v.laurendi@inail.it \\ * Correspondence: eugenio.cavallo@cnr.it; Tel.: +39-01-1397-7724
}

Received: 30 September 2017; Accepted: 28 November 2017; Published: 3 December 2017

\begin{abstract}
Following formal opposition by France, the harmonized safety standards regarding manually-loaded wood chippers (EN 13525:2005+A2:2009) which presumed compliance with the Essential Health and Safety Requirements (EHSR) required by the Machine Directive (Directive 2006/42/EC), have recently been withdrawn, and a new draft of the standard is currently under revision. In order to assess the potential impact of the expected future harmonized standards within the Italian context, this study has examined the main issues in implementing EHSRs on wood chippers already being used. Safety issues regarding wood chippers already in use were identified in an analysis of the draft standard, through the observation of a number of case studies, and qualitative analysis of the essential technical interventions. A number of agricultural and forestry operators and companies participated in the study, pointing out the technical and economic obstacle facing the safety features requested by the pending new standard. It emerged that the main safety issues concerned the implementation of the reverse function, the stop bar, and the protective devices, the infeed chute dimension, the emergency stop function, and the designated feeding area. The possibility of adopting such solutions mainly depends on technical feasibility and costs, but an important role is also played by the attitude towards safety and a lack of adequate information regarding safety obligations and procedures among users.
\end{abstract}

Keywords: safety; wood chippers; standards; machinery

\section{Introduction}

Farm machinery is an important contributor to the high rates of occupational injury in agriculture [1-4]. The tractor is the leading cause of accident in agriculture and the major proportion of injuries and deaths are associated with the rollovers [5,6]. Regarding non-tractor agricultural machinery, the most common causes of injury or death in farming are entanglement, crushing and shearing in machines [7]. Moreover, reports on accidents dynamics confirm that a very high number of occupational accidents in agriculture are caused by contact with moving parts such as rollers, conveyors and rotators [8-10]. In these circumstances, a lack of safety features such as manufacturer-made shields, guards, lids, and covers, generally defined as safety devices, contributes to machinery operators injuring upper and lower limbs in moving parts [11-13].

An additional factor regarding occupational injuries is the incorrect behavior of machine operators during field adjustment $[9,14,15]$ : for example, when removing obstructions from the machinery without turning off the machine or after removing protective devices [16]. This brings operators into close contact with components that may present a risk of entanglement $[15,17,18]$. Risky behavior is also the result of operators not reading operation manuals, particularly the safety warnings $[19,20]$ 
and often not noticing or understanding the safety instructions and the pictograms affixed on the machine [21,22].

Another significant determining factor that is statistically associated with injuries caused by farm machinery is the age of the machine in question [14]. There are a number of explanations for this: older units usually require more frequent maintenance interventions bringing users into intimate contact with hazardous parts (e.g., moving parts, cutting blades) which indirectly leads to a greater risk for injury $[14,23,24]$. Furthermore, a study by Baker et al. [25] demonstrated that for each year increase in the age of the machine the odds of injury rise by $4 \%$, particularly in machinery purchased second-hand. The same study concluded that older machinery is more likely to lack certain safety devices, or that those present are somehow deficient. Another study [11] found a correlation between the absence of safety devices and the age of the machine. Likewise, a study conducted in Italy [26], pointed out that among the main causes of accidents in the agricultural sector, the machinery itself is often intrinsically deficient and does not meet the safety requirements due to its age. Indeed, according to literature reports, a large proportion of in-use farm machinery is not equipped with the most up-to-date features required by safety standards [27].

In the Italian context, this scarce compliance with safety standards is mostly due to the economic size of farms. Although the average size of the Italian business has increased, the agricultural sector continues to be characterized by a large number of very small holdings [28]. In 2013, the average size of Italian farms ranged from 7.9 to 8.4 hectares [29], and farms smaller than 5 hectares accounted for $68 \%$ of the total [30] while in 2014, holdings with a standard value production of less than $€ 15,000$ represented $54.3 \%$ of the total number of farms in Italy [31].

\subsection{Manually Loaded Wood Chipper and Specific Hazards}

A number of studies indicate that the agro-forestry biomass production sector is characterized by a high incidence of injuries [32-35]. Focusing on this sector, wood chipping machines are the most common cause of crushing, entanglement and shearing hazards [36-38]. Wood chippers are employed in forestry, agriculture, horticulture, and landscaping, and turn wood into "wood chips" in order to reduce volume for subsequent disposal, or for use in bio-energy production $[39,40]$. There are a number of sizes available: the bigger units have a greater capacity, are usually equipped with their own engine and they are mechanically loaded by a telescopic arm. The smaller units are generally mobile types, trailed or carried by the tractor's rear three-point linkage and coupled with the rear power take-off (PTO) and are manually loaded [41].

Wood chippers basically consist of: (i) a horizontal or near horizontal infeed chute; (ii) infeed components such as rollers or conveyors; (iii) rotating chipping components (made of knives fitted on a drum or a disk), and (iv) a discharge chute. The wood logs or branches are loaded into the infeed chute, and feed rollers at the end of the infeed chute grasp the material and force it into the chipper cutting unit where the knives chip the wood and force the chips through a discharge chute. The chipper knives generally rotate between 1000 and 2000 revolutions per minute [37]. The chipping components container is usually equipped with a removable hood to allow access to the components for maintenance and repair. These smaller machines are generally employed by small businesses and contractors to reduce the volume of logs and branches of limited diameter.

Many of the manually-fed wood chippers are equipped with a mechanical feed control bar that activates the feed rollers when it is pulled [37]. The bar is a pressure-sensitive device usually mounted across the bottom and/or along the sides of the infeed chute for quick and easy activation. The bar should be designed and placed to avoid unintentional activation by a part of the operator's body in the event of entanglement, whereby the infeed action can be stopped. Agro-forestry wood chipping machines and operations present specific occupational hazards [42]; indeed they may be extremely dangerous and potentially life-threatening for operators should they become entangled in the chipping mechanism [36]. This risk is particularly high in manual infeed wood chippers since the operator works close to the infeed chute increasing the chance of contacts with the feeding or chipping 
components. Indeed the main hazards are related to careless contact with an unguarded infeed, chipping, and power transmission components, but operators can also become caught or snagged by material entering a wood chipper [36]. In many cases, if entangled, I is almost impossible to free oneself as, in an emergency situation, a number of factors-such as the speed of infeed system-may limit the operator's ability to access or activate a feed-stop device [36].

Little information is available regarding accidents involving manually-fed wood chippers in Italy [43]. On the European level, France released some recent data in which the "Bureau Santé Securite au Travail" (Occupational Health and Safety Office) of the French Ministry of Agriculture, Agrifood, and Forestry reported that a severe accident related to the use of wood chipper occurs at least once a year [44]. In most of the reported cases operators involved in the accidents were very young apprentices who did not follow the correct safety conduct. Additional figures refer to the United States where, in the last five years, 20 cases of accidents have been recorded, 15 of which were fatal [45].

\subsection{Motivation of the Study}

Following a formal opposition by France due to the number of severe and fatal accidents caused by the use of manually-fed wood chippers, on the 17 December 2014 the European Commission withdrew the harmonized standard EN 13525:2005+A2:2009 “Forestry machinery-Woodchipper safety" provided by CEN (the European Committee for Standardization). As a consequence of this European decision, application of this standard by a manufacturer no longer confers presumption of conformity [1] with the essential safety requirements according to the Machine Directive (Directive 2006/42/EC).

Conformity problems, however, also arise for wood chippers already on the market or in-use at the time the standard was withdrawn. This question is particularly pertinent in Italy where farm machinery is on average more than 20 years old [46] (ranging from 15 to 30 years depending on the farm size) and often older units, especially those manufactured before September 1996, without the CE mark, do not comply with some of the Essential Health and Safety Requirements (EHSR) of Machine Directive.

As is the case in other countries in the European Union, in Italy the implementation of fundamental safety requirements is mainly regulated by the Machine Directive and the Italian decree on Occupational Health and Safety (Legislative Decree 81/2008), in application of the European Framework Directive on Health and Safety at Work (Directive 89/391 EEC). In these regards, after 15 May 2008, all machinery, including agricultural and forestry machines, that no longer complies with safety standards and safety regulations should not be employed further. Therefore, regarding units currently in use, the Machine Directive urges farm employers, manufacturers, distributors, rental firms and dealers to assess whether their machinery complies with safety requirements and to adapt them according to the specific harmonized standards. The harmonized standards establish technical specifications considered suitable or sufficient in order to comply with the technical requirements provided by EU legislation [47]. Though European harmonized standards are not mandatory, application thereof is recommended since they provide compliance solutions and confer a presumption of conformity with the relevant essential health and safety requirements of the Machine Directive [48]. Within this framework, the compliance with the directive often leads to confusion amongst operators due to the lack of precise constructive directions, and this represents a serious issue for them, both in terms of technical and economic feasibility.

Based on these considerations, and in the light of the ongoing revision of the EN 13525 safety standard and considering the Italian situation of in-use farm machinery, it is important to verify the practical implementation of minimal safety measures on wood chippers currently in use, especially concerning the risk of getting caught or being pulled into the machinery and to draft measure to correct nonconformity issues. 
For this reasons, a study was undertaken for the following points:

1. to check the actual condition and hazards associated with in-use wood chippers and to assess the level of conformity with safety standards;

2. to analyze appropriate solutions to eliminate and/or reduce risks due to contact, entanglement, dragging, cutting and crushing with in-use wood chippers to ensure minimal safety requirements;

3. to point out the main technical and economic issues observed at the local level in implementing the possible technical solutions to achieve minimal safety requirements on machines currently in use.

The outcomes of the study will give a clearer picture of the safety level of machines currently in use in Italy, to check the potential impact of the envisaged new harmonized standards on them, and the possible adoption of technical solutions to achieve the minimal safety requirements outlined in Annex I of Machine Directive and in the harmonized safety standard.

\section{Materials and Methods}

The study lasted one year, from February 2016 to January 2017 in the Piedmont Region (North-West of Italy). This region is Italy's second for energy production from renewable resources (11.6\% of total national production in 2014) and the fourth for biomass production (10.5\%). The investigation was carried out in the provinces of Torino and Cuneo where $68.2 \%$ of the region's biomass is produced [49].

The study was divided into three main stages, specifically focusing commercial manually-loaded horizontal wood chippers: (i) analysis of regulations and standards for wood chippers, (ii) onsite inspection of in-use wood chippers, and (iii) individual in-depth interviews with operators in the sector.

\subsection{Analysis of Regulations and Standards for Wood Chippers}

The most relevant regulations and standards related to wood chippers and the identification of major hazards and typical accidents have been examined. A deeper analysis focused on EN 13525, the European harmonized standard specifically regarding manually-loaded horizontal wood chippers, it represents the main reference to assess potential conformity of units currently in use. Special attention was paid to the technical note on 28-29 May 2015 by the French Minister of Agriculture in which the proposals for the implementation of the standard are explained in 10 points, and the new features introduced through the first available drafts of the revised standard. The version of the standard used for this study was the sixth draft revision of the EN 13525, updated on 10 August 2016. The aforementioned documents are unpublished works that were made available to the researchers in the framework of the "Protection of machinery operators against crush, entanglement and shearing" (PROMOSIC) project funded by the Italian National Institute for Insurance against Accidents at Work (INAIL).

\subsection{Onsite Inspection of In-Use Wood Chippers}

A sample of mobile manually-fed wood chippers used in farms and in forestry cooperatives in Northwest Italy was examined. In-use machines were recruited through direct contacts and referrals by representatives of the sector. During the recruitment phase, a series of characteristics were considered in order to meet the targets of the study. Machines had to be mobile, manually-fed, with a horizontal infeed chute, powered by the tractor's power take off, equipped with integrated infeed components (rollers), and with disk-type chipping components. Thence, a notable number of potential participant were not included in the survey since, especially the forestry cooperatives, as they used larger machines with mechanically-fed systems, which therefore did not meet the targets of the study. Finally, six machines were selected for onsite inspection; those considered the most representative models of in-use manually-fed chippers generally available on farms and used by contractors. A range of brands and manufacturing years was chosen in order to take into consideration a wider array of 
cases. For this study, the machines were evaluated in terms of compliance with the most recent version of the revised draft of the EN 13525, in expectation of the future publication of a new harmonized standard. Therefore, following the standard requirements and updated sections, onsite measurements and pictures were collected to analyze older units and to carry out a qualitative analysis.

The most significant examples of nonconformity were pointed out and technical interventions to adapt the machinery to the safety requirements were identified. The machines were measured and inspected, with particular focus on the dimensions and the positions of safety devices, while functional tests to check the controls were filmed with a camera.

At this stage, one of the case studies was used to check the speed of the wood during infeed and reversing as an operator loaded a machine with tree logs. The analysis was set by recording how the different controls of the infeed components were activated. The measurements were taken while chipping three logs of pine (Pinus strobus L.), three, four, and five meters in length respectively at the machine's top infeed speed. Infeed rate was constant and the time period was measured from the moment the wood hit the blades, until all the wood had been completely chipped.

\subsection{Individual In-Depth Interviews with Operators of the Sector}

Finally, a number of individuals $(n=8)$ operating in the forestry sector-including manufacturers, suppliers, users and mechanical workshops operators-were interviewed to highlight major technical and economic obstacles against adopting solutions, in compliance with safety standards.

The participants to individual interviews were recruited from farms, forestry cooperatives and manufacturing companies; they were identified through direct contacts and referrals from farmers and agricultural services. Potential respondents were contacted by telephone and given a short description of the study. Prior to each interview, subjects were briefed on the purpose of the survey and their rights as research participants [7]. All respondents provided informed consent.

Key informant interviews were conducted by two researchers [50] through guided semi-structured interview techniques [7], designed to raise the following key points:

- $\quad$ perspectives on risks related to in-use wood chippers and potential accidents;

- opportunity to put align wood chippers currently in use with the requirements requested by the

Machine Directive and related standards the already in-use wood chippers;

- observations on the technical and economic implementation of revised safety standards.

During the interviews, one of the researchers played the role of moderator asking some open questions, while the second researcher took notes and asked further questions.

For the manufacturers-including representatives of two of Italy's biggest wood chippers manufacturers-a different approach was taken. They were asked about the main obstacles preventing them from aligning their products with safety standards and the draft of the standard was further discussed. A joint analysis was carried out on the various sections of the safety standard draft and the technical and economic feasibility of potential solutions to increase machinery safety was evaluated. The interviews lasted between 1 and $1.5 \mathrm{~h}$.

Finally, some more recurrent topics were selected to organize and summarize the results of individual interviews.

\section{Results}

\subsection{Regulations and Standards Analysis}

The most relevant detected innovations introduced in the draft (sixth revised draft of EN 13525) regarding the withdrawn harmonized standard (EN 13525:2005+A2:2009) are in relation to: 
- the functional and positional requirements of operator controls, such as infeed controls, lower and side protective device, top protective devices and emergency stops;

- the positional requirements of infeed components and chipping components, such as infeed chute, infeed conveyors, infeed rollers, and chipping mechanisms.

The safety aspects that the standard draft intends to improve are meant to fulfil essential health and safety requirements of Annex I of the Machine Directive, particular regarding points "1.3.7 Risk related to moving parts", and "1.3.8.2 Moving parts involved in the process" [51].

The revised draft provides a more extended version of Section 4.2 "Operator controls" and an additional Annex which summarizes the main features of the different Stop controls configurations. In particular, this section introduces a new safety device, the "Emergency stop", which the draft defines as a "manually actuated control device used to stop the hazardous functions of the machine as quickly as possible".

\subsection{Onsite Wood Chipper Inspections}

The recruited manually-fed wood chippers were all equipped with integrated infeed components (rollers) and disk-type chipping components with a variable number of knives (Figure 1). The mean age of the studied machinery was about 14.5 years. The oldest one was manufactured in 1989, and the most recent was manufactured in 2014.

All the six inspected machines had at least one element of nonconformity with regards to the risk protection standards required by the draft of the revised harmonized standard (Table 1).

Table 1. Summary of results of the inspections on in-use wood chippers with regard to how they conform to the revised version (6th revision draft) of EN 13525 standard.

\begin{tabular}{|c|c|c|c|c|c|c|}
\hline Section of the Standard & $\begin{array}{l}\text { Chipper } 1 \\
\text { (28 Years) }\end{array}$ & $\begin{array}{l}\text { Chipper } 2 \\
\text { (19 Years) }\end{array}$ & $\begin{array}{l}\text { Chipper } 3 \\
\text { (12 Years) }\end{array}$ & $\begin{array}{l}\text { Chipper } 4 \\
\text { (6 Years) }\end{array}$ & $\begin{array}{l}\text { Chipper } 5 \\
\text { (6 Years) }\end{array}$ & $\begin{array}{l}\text { Chipper } 6 \\
\text { (3 Years) }\end{array}$ \\
\hline$\S 4.2 .4$ Infeed controls & NC & NC & PC & PC & PC & PC \\
\hline $\begin{array}{l}\S 4.2 .5 \text { Location of lower and } \\
\text { side protective device(s) }\end{array}$ & NC & NC & NC & PC & PC & PC \\
\hline$\S 4.2 .6$ Top protective device & NC & NC & NC & NC & PC & PC \\
\hline$\S 4$ 4.2.7 Emergency stop & NC & NC & NC & NC & NC & NC \\
\hline $\begin{array}{l}\text { §4.3.3.1 Hazard related to } \\
\text { infeed and chipping } \\
\text { components }\end{array}$ & NC & NC & PC & $\mathrm{C}$ & $\mathrm{C}$ & C \\
\hline $\begin{array}{l}\text { \$4.3.3.5 Designated } \\
\text { feeding area }\end{array}$ & NC & NC & NC & NC & NC & NC \\
\hline $\begin{array}{l}\text { § 4.3.4.2 Risks due to infeed } \\
\text { speed and reversing of } \\
\text { infeed components }\end{array}$ & $\mathrm{C}$ & $\mathrm{C}$ & $\mathrm{C}$ & $\mathrm{C}$ & C & $\mathrm{C}$ \\
\hline $\begin{array}{l}\S 4.3 .4 \text { Risk due to } \\
\text { ejected objects }\end{array}$ & NC & $\mathrm{C}$ & NC & $\mathrm{C}$ & NC & C \\
\hline $\begin{array}{l}\S 4.3 .5 \text { Protection against access } \\
\text { to moving power } \\
\text { transmission parts }\end{array}$ & NC & NC & PC & $\mathrm{C}$ & $\mathrm{C}$ & C \\
\hline$\S 4.4 .2$ Hydraulic components & PC & PC & $\mathrm{C}$ & $\mathrm{C}$ & C & $\mathrm{C}$ \\
\hline $\begin{array}{c}\S 4.5 \text { Preparation for transport } \\
\text { and maintenance }\end{array}$ & NC & NC & $\mathrm{C}$ & NC & NC & $\mathrm{NC}$ \\
\hline
\end{tabular}

$\mathrm{C}=$ conform, $\mathrm{PC}=$ partially conform, $\mathrm{NC}=$ non-conform. 


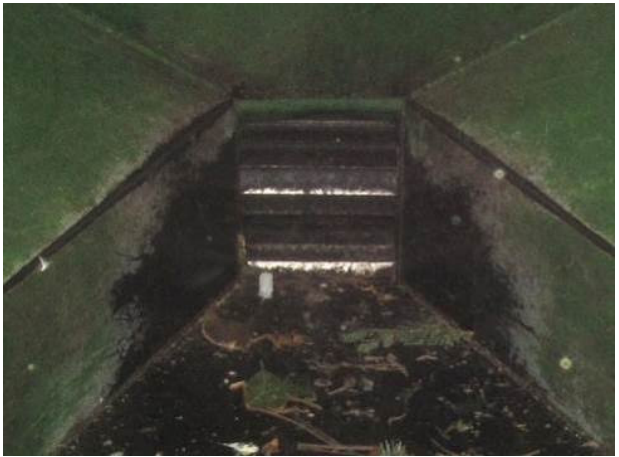

(a)

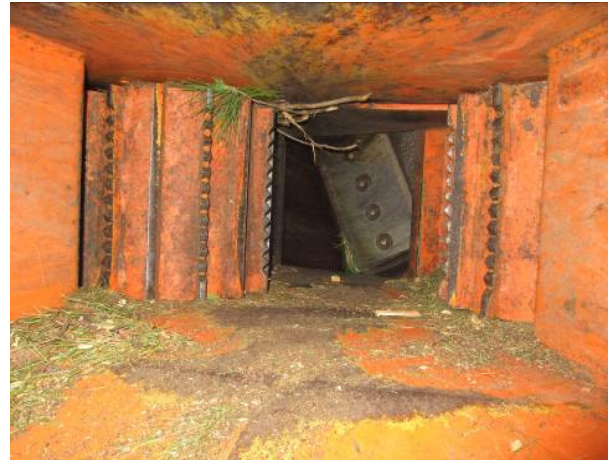

(b)

Figure 1. Detail of infeed components (rollers) (a) and knife on the disk shaft (b) of the surveyed in-use wood chippers.

\subsubsection{Nonconformities Relating to Entanglement, Crushing and Shearing Hazards}

- Infeed controls (§ 4.2.4-6th revision draft of EN 13525)

Although the control mechanism of all machines included the three compulsory functions ("Feed", "Stop", and "Reverse") some position and functional requirements were disregarded. The infeed area was not always visible due to the design of the chute and the control bar. Indeed, in one instance (Figure 2) the upper part of the chute was prolonged by a plate and was encased by a bulging safety bar that did not allow a direct view of the infeed area. Moreover, the positions and functions of operator controls were not always clearly indicated, while these should have been affixed near the control device on both sides of the chute. Especially in older units, respective safety pictograms were deteriorating or missing altogether (Figure 2).

With regard to functional requirements, even in the most recent examined units, the "Reverse" function was not provided with the "hold to run" function.

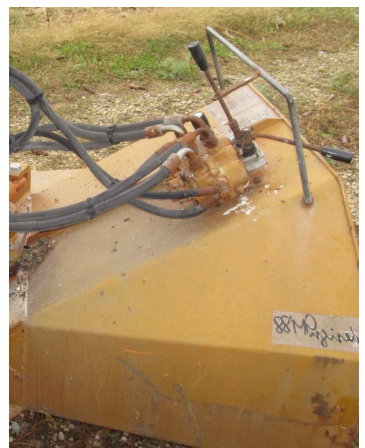

(a)

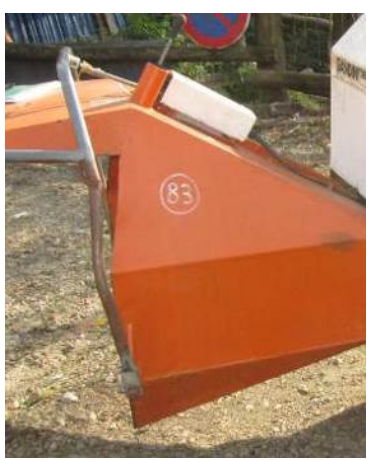

(b)

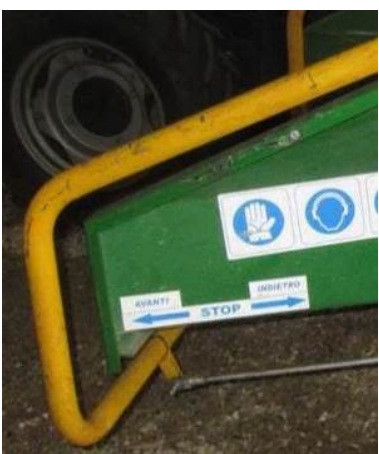

(c)

Figure 2. Examples of non-compliant infeed controls for in-use wood chipper. Details shown in figure (a) and (b) highlight the lack of any indication of machine operator controls; while figure (c) shows that the pictograms are placed in the correct position, but the functional requirements are not. Each of the examples included the reverse function but there was no "hold to run control" as requested by the paragraph 4.2.4.3 of the 6th revision draft of EN 13525.

- Location of lower and side protective device(s) relative to the infeed chute edges (§ 4.2.5-6th revision draft of EN 13525)

Half of the machines inspected completely lacked or presented incomplete lower horizontal and side vertical protective devices around the infeed chute edges (Figure 3). These protective devices 
should be designed and positioned in such a way that minimizes inadvertent activation by wood and branches as they are fed into the machine; at the same time, if entangled in the feed chute, the operator should be able to engage the lower and side protective devices involuntarily with a body part, not just their hands.

The safety devices in the oldest of the units were not red and yellow as recommended by the standard nor were they in bright colors contrasting with the background color of the infeed chute. In those cases, when lower and side protective devices were present, these did not always comply with the location regulations. In particular, regarding side protective devices, in some cases the distance from the outermost edge of the infeed chute was shorter than the standard $150 \mathrm{~mm}$ and did not cover at least the $75 \%$ of the maximum vertical opening of the infeed chute.

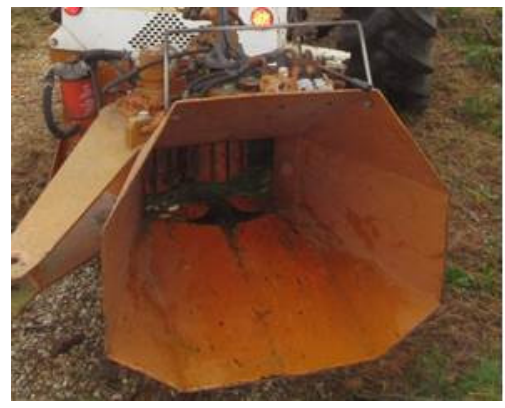

(a)

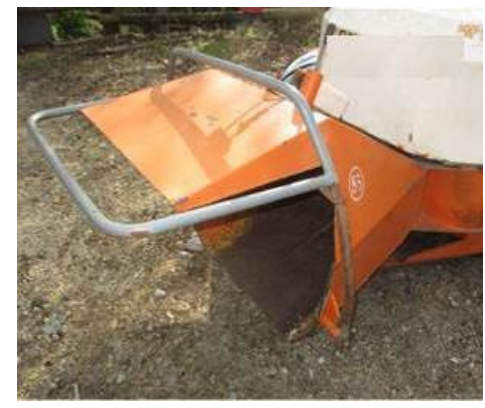

(b)

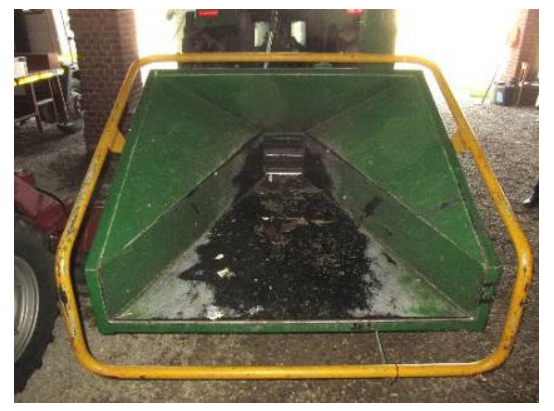

(c)

Figure 3. Some examples of protective devices that do not comply with standard requirements. (a) This machine presented no safety devices around the edges of infeed chute. (b) Side and upper protective devices were present, but there was no lower protective device (mandatory for the standard). (c) The infeed chute was equipped with side, lower and top protective devices, but in order to comply with the safety standard draft, the top protective bar should have a separate control or be replaced by an emergency stop.

- $\quad$ Top protective device (§ 4.2.6-6th revision draft of EN 13525)

The standard revised draft obliges all machinery to be equipped with a Top protective device consisting of one or more different devices that have the exclusive function of halting the infeed components. Unlike lower and side protective devices, the top horizontal bar is for intentional activation from both sides outside of the chute and from the ground. Among the examined case studies, a third of the verified machines did not have any top protective device, while in other cases where a top bar was provided, it was not completely independent from the other controls, meaning that it defaulted on one of the main functional requirements (Figure 4). The combination of a top protective device with other controls prevents a further condition: the operator cannot restart the infeed process merely by returning the top stop protective device to any position. In those machines surveyed that were equipped with the top protective device, the top bar is connected to the functional requirements and follows the same control patterns of the lower and side protective devices, meaning that the infeed action cannot be activated by a separate control. Likewise, for the lower and the side protective bars, the color of the protective device was not always respected. 


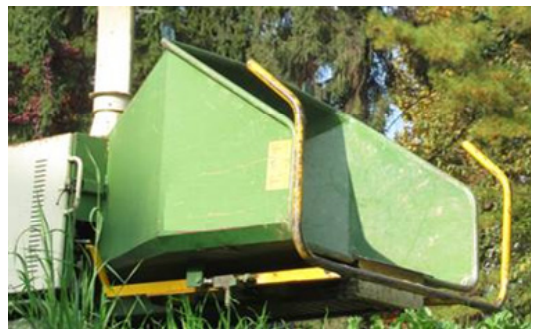

(a)

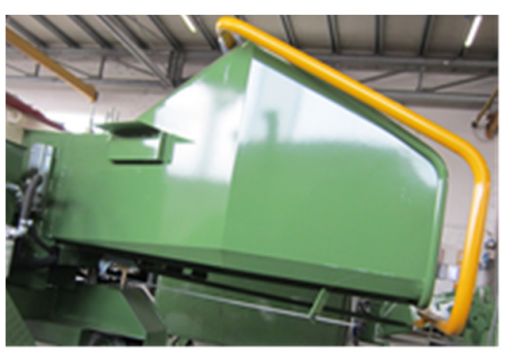

(b)

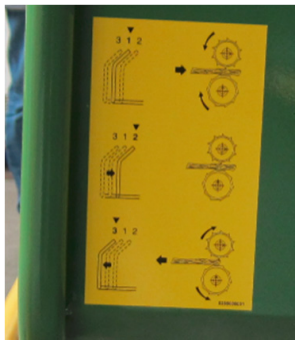

(c)

Figure 4. Examples of the different configurations of protective devices. On the left (a) the chute was found non-compliant due to the lack of a top protective device while in a more recent unit (b) the top protective bar is combined with side and lower protective devices and these respond to the same controls (c). This solution does not conform to the standard either as the top protective device should be independent and there are no emergency stops.

- $\quad$ Emergency stop (§ 4.2.7-6th revision draft of EN 13525)

The emergency stop is a manually-activated control device that differs from other protective devices. Of all the machines surveyed, including the most recent, none of them was equipped with an emergency infeed stop, which is expected to be introduced in the revised standard.

- Hazard relating to infeed components and chipping components (§ 4.3.3.1—6th revision draft of EN 13525)

According to the standard, the height of the chute floor should be $600 \mathrm{~mm}$ from the ground and the chute itself should be $1500 \mathrm{~mm}$ deep, machines with a lower chute height and/or depth are hazardous as the operator can easily get their hands or feet stuck in the moving parts. In half of the infeed chutes inspected, the lower edge of the infeed chute was insufficiently distant from the ground, and in one instance the horizontal distance from the outer edge of the chute to the reference plane-corresponding to the feeding rollers—-was not deep enough (Figure 5).

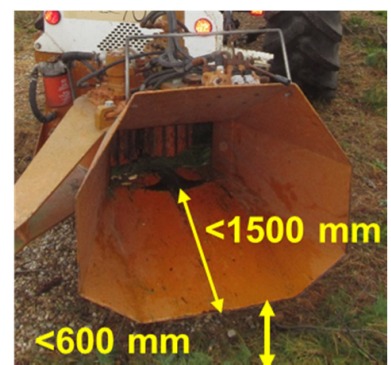

(a)

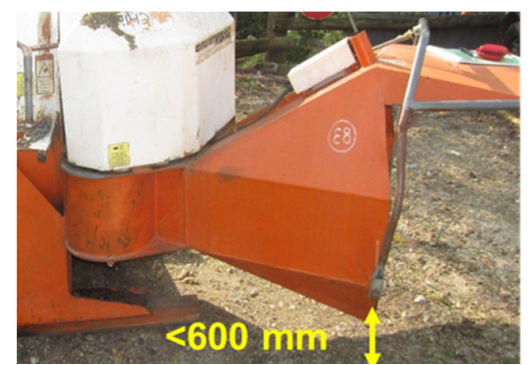

(b)

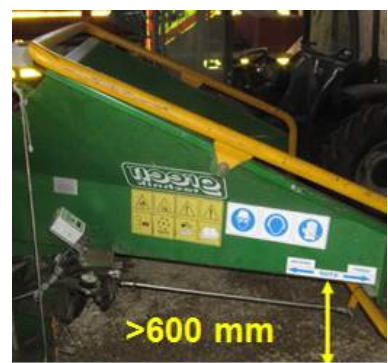

(c)

Figure 5. Case studies of infeed chute of in-use wood chippers. Following onsite measurements, in the first case (a) the lower edge of the infeed chute was lower than $600 \mathrm{~mm}$ from the ground and the chute was less than $1500 \mathrm{~mm}$ deep, in the second example (b) only the height of chute did not conform to standard requirements, while, in the last example (c) all positional measurements of infeed components were satisfactory.

- Designated feeding area (\$4.3.3.5—6th revision draft of EN 13525)

The designated feeding area is defined in the standard as "one or more safe areas around the machine indicated by the manufacturer when the operator is manually feeding the machine" and it is particularly important since as it is used as a reference point in defining the positional requirements of operator controls. This area should be determined by the manufacturer, but in the samples examined, the machines lacked clear indications as requested by the standard (Figure 6). 


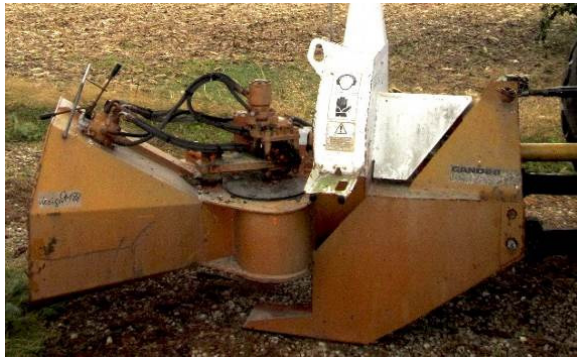

(a)

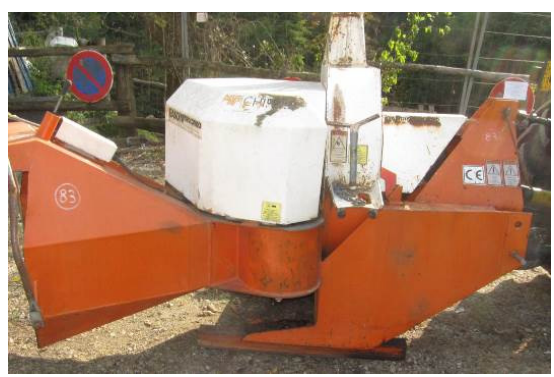

(b)

Figure 6. Specimens of the same model of wood chipper manufactured in different years on which lacked feeding area identification and safety pictorials were worn or incomplete. Moreover on (a) the hydraulic components are freely accessible while in (b) they are housed in a metal protection case.

\subsubsection{Other Nonconformities Relating to Mechanical and Non-Mechanical Hazards}

During the on-site verifications, a number of nonconformities, regarding hazards other than those related to infeed and chipping devices were detected, namely: risks due to ejected objects, risks due to moving power transmission parts, and risks due to non-mechanical hazards (e.g., hydraulic components, see figure 6). Though these kind of risks were not the core target of the study, they are worth reporting as they contribute to a clear overall view of the complete range of cases in which harmonized standard requirements are not observed by machines currently in use.

- Risks due to infeed speed and reversing of infeed components ( $\$ 4.3 .4 .2-6$ th revision draft of EN 13525)

On the machines under inspection, the speed of wood tested below the limit of the maximum nominal speed of $1.0 \mathrm{~m} \mathrm{~s}^{-1}$ defined in the standard. The average speed of the tested logs was $0.2 \mathrm{~m} \mathrm{~s}^{-1}$ (Figure 7). The time wood takes to travel from the outermost edge of the chute to the rollers is particularly significant as it is closely tied with the time required by the standard for protective devices to stop infeed components. Increase in wood speed increases the speed of entanglement and reduces the reaction times for dealing with a dangerous situation.

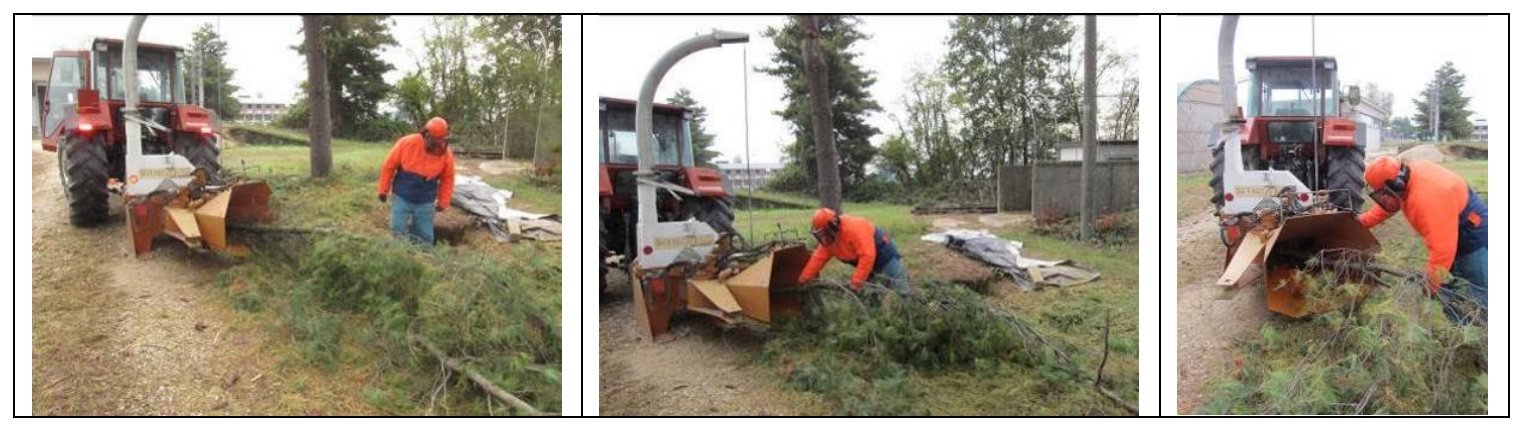

Figure 7. Images of the procedures followed during the wood speed test, operated with a 28-years-old wood chipper.

- $\quad$ Risk due to ejected objects (§ 4.3.4 6th revision draft of EN 13525)

When chipping, discharge chute rotation should be limited to 20 degrees from a line drawn through the center of rotation and the outer edge of either side of the infeed chute. In some specimens of wood chippers inspected, it was possible to direct the discharge chute over the infeed chute, and in one case in particular, no obstacles were present to limit the rotation (Figure 8). 


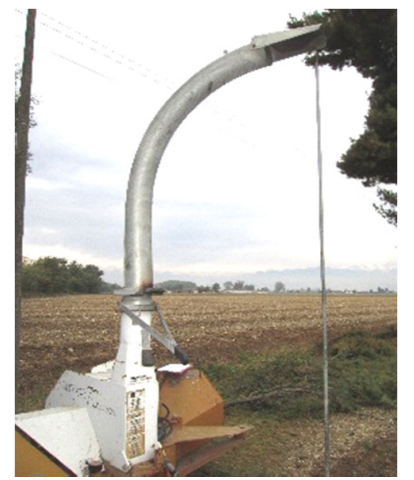

(a)

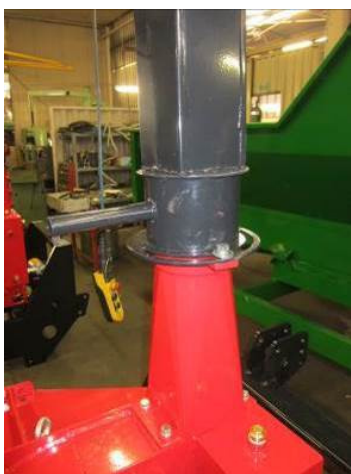

(b)

Figure 8. In some of the study cases (a) and (b), the discharge chute could be fully rotated, therefore well beyond the limit defined by the standard draft.

- Protection against access to moving power transmission parts ( $\S 4.3 .5$ 6th revision draft of EN 13525)

All the machines inspected were powered by a tractor PTO. In two cases, moving power transmission parts were not adequately shielded by fixed repair such as a PTO safety shield (Figure 9).

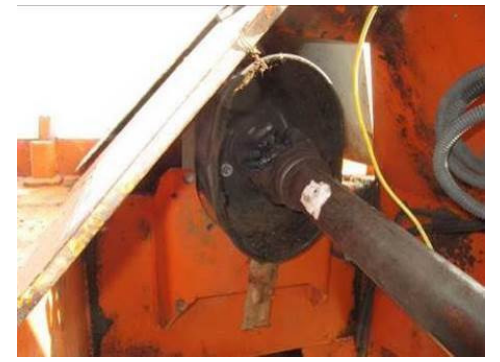

(a)

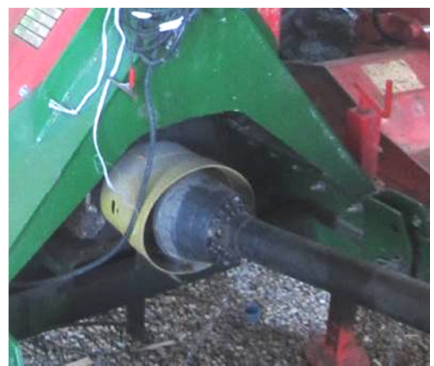

(b)

Figure 9. Example of observed unshielded power take-off (PTO) shafts (a) and partially shielded PTO (b) Hydraulic components (§ 4.4.2 6th revision draft of EN 13525).

In all the units inspected, hydraulic components were protected by a hood, but in the case of the two oldest units, the protective hood was merely hinged rather than bolted with interlocks, meaning that it was not firmly fixed to the machine (Figure 10).

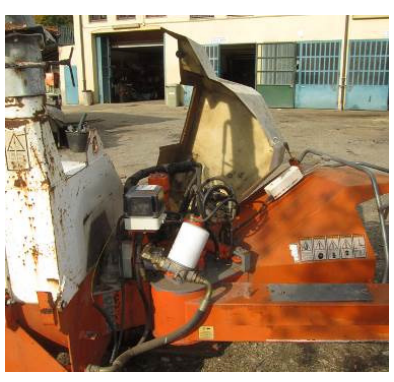

(a)

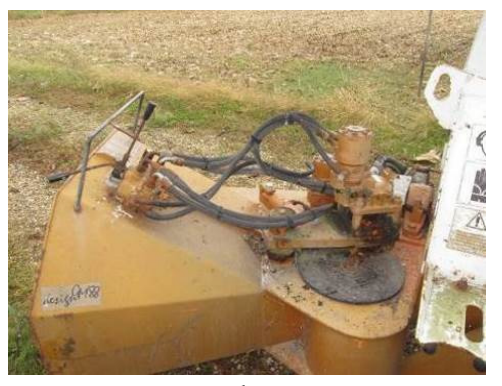

(b)

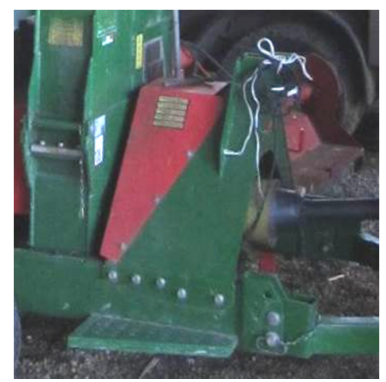

(c)

Figure 10. Observed case studies of wood chippers: pictures (a) and (b) show chippers equipped with an easily removable hood that, when open, leaves the hydraulic lines without protection, on the right (c) a case study with a fixed repair (bolted hood). 
- Preparation for transport and maintenance ( $\$ 4.56$ th revision draft of EN 13525)

The infeed and discharge chutes/conveyors lacked handles near the articulation point to be easily folded for transport or maintenance (Figure 11). Even though this solution is not a hazard prevention device in any way, in terms of safety standard compliance, the implementation of required features has economic implications.

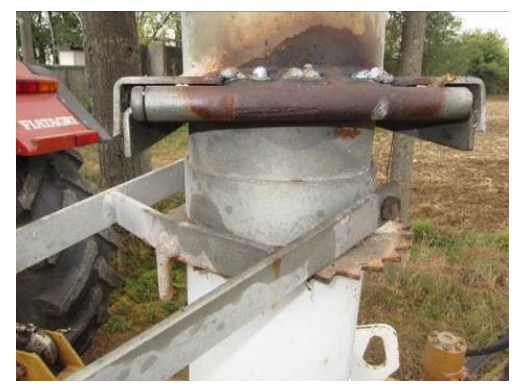

(a)

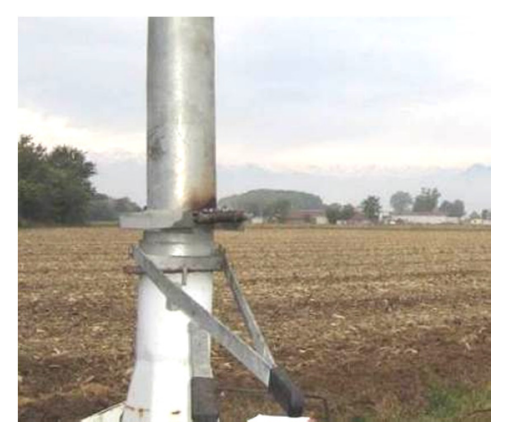

(b)

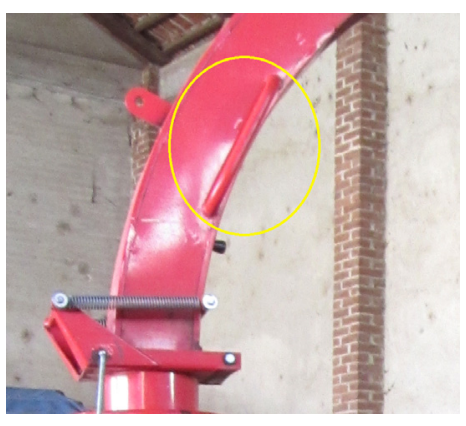

(c)

Figure 11. The discharge chute of the examined machine (a) and (b) was lacking in the two handles requested by the standard draft. These should be located at a distance of at least $300 \mathrm{~mm}$ from the nearest articulation point as shown in the picture on the right (c).

\subsection{In-Deph Interviews}

In-depth interviews highlighted a number of critical aspects that hindered the implementation of safety standards on in-use wood chippers. Based on the analysis of the participants' interviews, five prominent themes appeared to be highly relevant for users and manufacturers of wood chippers and could provide a helpful recommendation for future interventions. These themes were: "the reverse function", "the stop bar and the protective devices", "the infeed chute dimension", "the emergency stop", and "the designated feeding area". In addition to these themes, a feasibility and costs analysis of some solutions was provided (Table 2).

Table 2. List of the most probable costs to adapt in-use wood chippers to the most recent available revision draft of harmonized standards. Costs refers to average costs proposed for the Northwest Italy market.

\begin{tabular}{|c|c|c|c|}
\hline $\begin{array}{l}\text { Section of the Standard EN } \\
13525\end{array}$ & Solution for Adaptation to Standard & Costs & $\begin{array}{c}\% \text { on Average } \\
\text { Purchasing Price }{ }^{1}\end{array}$ \\
\hline \multirow[t]{3}{*}{$\S 4.2 .7$ of 6th revision draft } & Installation of electrovalve "no stress" device & $€ 250$ & $3.6 \%$ \\
\hline & $\begin{array}{l}\text { Installation of emergency stop } \\
\text { push-button control }\end{array}$ & $€ 200$ & $2.9 \%$ \\
\hline & $\begin{array}{l}\text { Installation of complete emergency stop system } \\
\text { (including hydraulic lines and labor) }\end{array}$ & $€ 1.000-1.500$ & $14.5-21.7 \%$ \\
\hline$\S$ 4.3.3.1 of 6 th revision draft & Extension of the plate machine's infeed chute & $€ 600$ & $8.7 \%$ \\
\hline $\begin{array}{l}\S 4.3 .5 \text { and } \S 4.4 .2 \text { of } 6 \text { th } \\
\text { revision draft }\end{array}$ & $\begin{array}{l}\text { Application of a bolted hood to protect from } \\
\text { hot components and moving power } \\
\text { transmission parts }\end{array}$ & $€ 150-200$ & $2.2-2.9 \%$ \\
\hline$\S 4.2 .4$ of 6th revision draft & Substitution of hydraulic distributors & $€ 300$ & $4.3 \%$ \\
\hline$\S 4.5$ of 6 th revision draft & $\begin{array}{l}\text { Application of a hinge in order to ease folding } \\
\text { for transport or maintenance of the discharge } \\
\text { chutes/conveyors }\end{array}$ & $€ 300$ & $4.3 \%$ \\
\hline
\end{tabular}

${ }^{1}$ The average price refers to chippers similar to those surveyed in this study. 


\subsubsection{The "Reverse" Function}

According to the last revision draft of the standard, the "reverse" function should always be hold-to-run, but for the moment, this condition is not available on current machines. In fact, as observed during the onsite inspection, in most cases the "reverse" function is activated by a maintained position and it is mechanically controlled. With regard to this issue, both users and manufacturers expressed some perplexities about the standard's required implementation but also about its functionality. Generally speaking, respondents found difficulty in understanding the section of the revised draft that shows the combination of infeed controls allowed for lower protective devices. In particular, a couple of final users interviewed contested the worth of an optional reverse function beyond the chute edge, but this was probably because they were accustomed to other control configurations.

Finally, one of the two manufacturers consulted proposed a feasible solution involving working on the control of the existing hydraulic distribution system. If the hydraulic distributors are to adapt to the safety requirements imposed by the draft, they must be replaced in a sustained position by others, thereby providing the "hold to run" control.

\subsubsection{Stop Bar and Protective Devices}

The manufacturers reported that, currently, the safety bars (the lower, side protective devices and the top stop bar) are mechanical devices that insist on hydraulic lever distributors. In a number of current wood chippers, the protective bars respects positional requirements: they cover the full width of the infeed chute and up to a minimum of $75 \%$ of the vertical opening of infeed chute; but regarding functional requirements, many systems would need to be revised. The combined controls associated with the protective devices may vary according to the design adopted by the different manufacturers. Among some of the companies surveyed, infeed chute models work as a "swinging bar": the lower bar, if pushed forward, allows the conveyors to stop, while the upper one works in reverse as it needs to be pulled to halt the machine. Manufacturers explain this choice as the top bar, in accordance with the previous version of the harmonized safety standard, currently acts as a "connection and reinforcement" of the protective device rather than as an emergency stop. This mechanism does not meet the safety requirements of the latest revised standard as it may prove confusing during an emergency.

\subsubsection{Infeed Chute Dimension}

The standard demands set dimensions for the infeed chute and precise distances from the ground. The manufacturers interviewed confirmed that they were aware of the standard conditions and dimension requirements regarding wood chippers, as referred to in the previous version of the standard. Most of the recently designed models of manually-fed wood chippers do fulfil such conditions, while the older ones require intervention for compliance of different level of complexity. Both users and manufactures pointed out potential issues related to the stability of the machine in the event of interventions, such as increased infeed chute height and extended chute depth.

\subsubsection{Emergency Stop}

At present, almost no existing wood chippers are equipped with a separate emergency stop device as set out by the standard. However, some users interviewed reported having seen in agricultural machinery exhibitions that a number of manufacturers have already equipped their machines with emergency stop devices.

The manufacturers and technicians interviewed reported that the majority of operator controls are mechanical or hydraulic. The installation of an emergency stop push-button control, which is maintained by a separate control until reset, requires an electronic component. The addition of this safety system requires the installation of an electro-hydraulic valve and an electric power supply. Currently, some machines are already equipped with the so-called "no-stress" device. This device acts on the power supply of the machine by inverting the direction of rotation of the feed rollers when 
the rotation speed of the cutting device, the drum or the disk, drops below a set point. The device's electronic system act on the electrovalve that controls the activation of chipping components or of infeed conveyors. On those machines already equipped with this device, the installation of a safety system does not entail particularly costly interventions.

\subsubsection{Designated Feeding Area}

According to the majority of respondents, manufacturers, workshops and end-users, the position from which the operator should feed the chipper, as outlined in the draft, is in practice difficult to achieve, especially if the chipping material is particularly heavy. This suggests that even though the manufacturer may clearly mark the area with specific pictorials on the machine, the position itself is often disregarded. In order to prevent loading from the front of the chute, which increases the risk of the operator being caught in the machine, the only effective solution would be to impose side-loading by modifying the design of the infeed chute. According to the respondents this would be hardly feasible on in-use wood chippers.

\subsubsection{Identified Solutions and Cost Analysis}

As a result of the information provided by the interviews with professionals, an array of possible interventions to ensure essential safety requirements was identified and for some of these solutions possible adjustment costs were obtained (Table 2). The proposed costs relate to the average costs proposed by the workshops visited and hypothesized by the technical staff of some manufacturers. Even though the proposed costs appeared relatively affordable for most businesses, these may vary considerably according to the age and the state of the machine.

\section{Discussion}

Agricultural machine design is in continuous evolution, and attention has increasingly been paid to safety in recent years [52]. Huge progress has been made in safety and ergonomics since the 1980s [53]. Regarding machinery this evolution culminated in the introduction of the first Machine Directive (89/392/EEC), the first set of regulations meant to ensure a common safety level in manufactured machinery. In following years, a new edition of the Machine Directives came into force, safety regulations have become more demanding [54] and machinery safety has become one of the targets of the technological evolution [53]. The development of safety standards and regulations in recent years contributed to a higher level of safety in new machines compared to their older counterparts [27]. In this context, in compliance with the Machine Directive the same level of safety should be guaranteed for agricultural machinery currently in use, even that which is technologically inferior.

The focus of this study was: (i) to develop a more in-depth understanding of the current conditions and hazards associated with in-use manually fed wood chippers, assessing the conformity thereof with the revised draft of safety standard EN 13525; (ii) to evaluate within this context the possible consequences of new pending standard implementation, pointing out the main issues, actual feasibility, and the costs that this implementation involves. Moreover, the study highlighted solutions to achieve the required level of safety for operators, while verifying the effective technical feasibility and the economic impact of some.

Results confirmed that, in the area under survey (considered representative of the Italian context), the majority of wood chippers currently in use would not comply with the most recent available draft of standard, especially regarding protection against the risk of entanglement. This condition is not limited to the Italian context; indeed, international literature related to forestry industry reveals other examples of partial compliance to safety standards. Some studies carried out in New England, in USA, [55,56], assessing the adherence to the American National Standards for Arboricultural Operations (ANSI Z133.1-2006), found low levels of compliance to chipper safety standards across all surveyed arborists company types. 
Interviews confirmed that the potential impact of the pending new standard is of notable significance for companies. Individual interviews with operators identified the following items as the most problematic: the reverse function", "the stop bar and the protective devices", "the infeed chute dimension", "the emergency stop", and "the designated feeding area". These items proved difficult to put into practice mainly due to the technical feasibility and economic issues involved, but the attitude towards safety and lack of information also play an important role.

\subsection{Technical Feasibility}

With regards to the technical feasibility of pending safety standard requirements, the manufacturers interviewed were able to identify some possible and operative solutions. Nevertheless, while admitting the potential feasibility thereof, they also suggested that the intervention could become more difficult as the machine aged. In particular, some solutions proposed in the harmonized standard regarding emergency stops were only possible on electronic machines able to operate on hydraulic lines controlling the infeed components. In this case, technical implementation proved very difficult on the oldest units, since any modifications may be incompatible with mechanical components or structural parts.

\subsection{Economic Issues}

Though the costs proposed for the constructive modification hypothesized in this study could be considered affordable for most businesses, these may vary considerably depending on the condition of the specific machine. Generally speaking, the economic issues and the size of the farm/company often represents a barrier to the adoption of safety measures. In practice, debate with users and producers, confirmed that, as in Italy most companies and farms are small or medium size, are unable to bear additional costs for machinery interventions [14,57]. Hagel et al. [58] identified associations between higher levels of "economic worries" and the absence of safety shields on grain augers. Moreover two studies by Cavallo et al. $[28,54]$ demonstrated that in fact the larger the farm, the more interest shown in technological innovations aimed towards improving safety for machinery operators. A study by Fargnoli et al. [27] confirmed that small Italian agricultural and forestry companies are less willing to invest in initiatives aimed at improving safety at work.

\subsection{Safety Attitude}

Both the machinery inspections and interviews established that operators are aware of the hazards but at the same time, they perceive standards and regulations as a bureaucratic encumbrance rather than a means to improving working conditions in terms of safety. Operators appeared skeptical about the actual efficacy of newly-introduced standard requirements and proved particularly frustrated by safety solutions interfering in the management of their working activities on the operative level. This complies with a study by Weil et al. [7] on PTO driveline shielding, in which farmers were interviewed and reported that limited time and resources make work safety unfeasible and that "anything that interferes with getting the job done, or that costs more time and money, has a definite impacts on the livelihood of the farmers". These factors encourage farmers to believe that it is the better to rely on common sense, best practices and experiences rather than technical wood chipper protective devices.

Similar outcomes were found by Caffaro et al. [59] during the survey on perceived machineryrelated risks and safety attitudes in senior Swedish farmers: respondents mainly referred to the common sense and previous experience as the best safety practices. These dynamics were very close to and consistent with many other studies related to the use of protective devices such as PTO shielding and use of Roll Over Protective Structures (ROPS) on tractors [60-63].

\subsection{Lack of Information}

As it emerged from the study, a lack of information and of precise constructive instructions, especially among farmers and users, makes it difficult for operators to consistently conform to 
up-to-date regulations. Additionally, it may be the case that the harmonized standard is not entirely clear for all professionals and whether or not a safety feature should be considered compliant with the Machine Directive becomes a matter of discretion [57]. With this regards, Fargnoli et al. [27] also pointed out the lack of knowledge and expertise in both risk assessment and safety management among operators and ascribed this to the large number of elderly farmers or foreigners, who have rarely received professional training. In fact, as some authors suggest [3], educational programs are the main approach to undertake in order to improve the safety practices of farmers.

Generally speaking, the operators interviewed turned out to be completely extraneous to the legislative background and the revision process of safety standards. Only manufacturers proved aware of the standard withdrawal as, in their role as machine producers, they had participated in European discussion boards. With regard to this last consideration, thanks to this study it was possible to obtain an important perspective (especially from manufacturers) and highlight the gap between European regulation and the execution of safety requirements on the machines currently in use.

\subsection{Limitations of the Study}

This study intended to reflect the current scenario of the potential application of revised safety standard in Italy, but it does presents some limitations. The sample group was represented by a limited number of case studies from the North West of Italy. Nevertheless, with regard to the category of manually-fed wood chippers, it is representative of in-use models of machinery generally available on farms and used by contractors in Italy. Inferences to larger scales or other context should consider this limitation. Currently, individual interviews were only carried out with key informants from the Piedmont region and although it is the second highest producer in Italy and the manufacturers involved are two of the most important Italian companies in the sector, the qualitative information collected during the interviews and the frequency of the issues raised cannot be generalized.

Additional limitations are given to the fact that occupational safety in agricultural in-use machines is a very sensitive topic. In fact, information collected about the respondents' safety behaviors and perspectives on safety issues and regulations may have been subject to bias towards more "socially desirable" answers.

As far as onsite verifications are concerned, a further functional test could have been carried out. The force required in activating protective devices should subject to testing. According to the standard draft this should not exceed $150 \mathrm{~N}$ on the horizontal parts of infeed controls and $200 \mathrm{~N}$ on other parts along the length. The functional tests carried out during this study on infeed controls and protective devices, let suppose that in some of inspected in-use machines the force required was higher than the maximum values stated by the standard.

Moreover, the study just concentrated on the revised draft of the harmonized safety standard for wood chippers (EN 13525) and improved safety for operators regarding the risk of getting caught and drawing into the machinery without taking into consideration other significant risks related to the use of manually-fed wood chippers, such as physical exposure to ergonomic hazards. In fact, operators loading the machines are prone to musculoskeletal disorders since they often undergo awkward postures, repetitive movements and frequent lifting of loads thus could; for this reason, further studies in this matter in particular could prove useful.

\section{Conclusions}

This study examined various technical features for reducing or eliminating risks related to entanglement, crush, and shearing on in-use wood chippers. Solutions were obtained based on the observation of a number of case studies and on the qualitative analysis of the essential technical interventions needed to increase the intrinsic safety level of machinery currently in use.

The study confirms that the majority of interventions required for wood chippers currently in use are technically feasible and affordable for most companies. Nevertheless, the complexity and costs of interventions increase with the age of the machinery. In particular, some solutions proposed by the 
reference standard regarding emergency stops would only be possible on machines equipped with an electronic system that can operate on hydraulic lines controlling the infeed components. In this case, technical implementation would be very difficult on older units, since any modification may prove incompatible with mechanical components or structural parts. Moreover, adaptation to current safety standard could prove economically unfeasible on smaller units with little market value, despite being most likely of wide-spread use in small-medium sized farms and cooperatives throughout Italy.

Acknowledgments: This study was carried out within the framework of "Protection of agricultural machinery operators from crush, entanglement, shearing" (PROMOSIC) project, funded by INAIL.

Author Contributions: Vincenzo Laurendi and Eugenio Cavallo conceived the study, Giorgia Bagagiolo and Eugenio Cavallo designed the study, Giorgia Bagagiolo and Eugenio Cavallo performed the study, analyzed the data collected, and drafted the manuscript. Eugenio Cavallo coordinated the study and critically revised the manuscript for its theoretical and intellectual content.

Conflicts of Interest: The authors declare no conflict of interest.

\section{References and Note}

1. Alt, N. International agricultural machinery standards for the benefit of agriculture and industry. In Proceedings of the 24th Annual Meeting of Club of Bologna, Hannover, Germany, 10-11 November 2013; pp. 1-4.

2. McCurdy, S.A.; Carroll, D.J. Agricultural injury. Am. J. Ind. Med. 2000, 38, 463-480. [CrossRef]

3. Layde, P.M.; Nordstrom, D.L.; Stueland, D.; Brand, L.; Olson, K.A. Machine-related occupational injuries in farm residents. Ann. Epidemiol. 1995, 5, 419-426. [CrossRef]

4. Day, L.; Voaklander, D.; Sim, M.; Wolfe, R.; Langley, J.; Dosman, J.; Hagel, L.; Ozanne-Smith, J. Risk factors for work related injury among male farmers. Occup. Environ. Med. 2009, 66, 312-318. [CrossRef] [PubMed]

5. Görücü, S.; Cavallo, E.; Murphy, J.D. Perceptions of tilt angles of an agricultural tractor. J. Agromed. 2014, 19, 5-14. [CrossRef] [PubMed]

6. Cavallo, E.; Langle, T.; Bueno, D.; Tsukamoto, S.; Görücü, S.; Murphy, J.D. Rollover Protective Structure (ROPS) retrofitting on agricultural tractors: Goals and approaches in different countries. J. Agromed. 2014, 19, 208-209. [CrossRef]

7. Weil, R.; Mellors, P.; Todd, F.; Sorensen, J.A. A Qualitative Analysis of Power Take-Off Driveline Shields: Barriers and Motivators to Shield Use for New York State Farmers. J. Agric. Saf. Health 2014, 20, 51-61. [CrossRef] [PubMed]

8. Aneziris, O.N.; Papazoglou, I.A.; Konstandinidou, M.; Baksteen, H.; Mud, M.; Damen, M.; Bellamy, L.J.; Oh, J. Quantification of occupational risk owing to contact with moving parts of machines. Saf. Sci. 2013, 51, 382-396. [CrossRef]

9. Gerberich, S.G.; Gibson, R.W.; French, L.R.; Lee, T.Y.; Carr, W.P.; Kochevar, L.; Renier, C.M.; Shutske, J. Machinery-related injuries: Regional rural injury study-I (RRIS-I). Accid. Anal. Prev. 1998, 30, 793-804. [CrossRef]

10. Al-bassit, L.; Tricot, N. Improvement of Manure Spreaders Safety. Feasability Study; Irstea Report; IRSTEA: Antony Cedex, France, 2013.

11. Purschwitz, M.A.; Stueland, D.T.; Lee, B.C. Feasibility Study of Inspection of Farm Machinery Safety Features. J. Agromed. 1994, 1, 29-38. [CrossRef]

12. Pickett, W.; Hagel, L.; Dosman, J.A. Safety features on agricultural machines and farm structures in Saskatchewan. J. Agromed. 2012, 17, 421-424. [CrossRef] [PubMed]

13. Narasimhan, G. Machinery-Related Operational Factors as Determinants of Injury on Canadian Prairie Farms; Queen's University: Kingston, ON, Canada, 2009.

14. Narasimhan, G.R.; Peng, Y.; Crowe, T.G.; Hagel, L.; Dosman, J.; Pickett, W. Operational safety practices as determinants of machinery-related injury on Saskatchewan farms. Accid. Anal. Prev. 2010, 42, 1226-1231. [CrossRef] [PubMed]

15. Narasimhan, G.; Crowe, T.G.; Peng, Y.; Hagel, L.; Dosman, J.; Pickett, W. A Task-Based Analysis of Machinery Entanglement Injuries among Western Canadian Farmers. J. Agromed. 2011, 16, 261-270. [CrossRef] [PubMed]

16. Chinniah, Y. Analysis and prevention of serious and fatal accidents related to moving parts of machinery. Saf. Sci. 2015, 75, 163-173. [CrossRef] 
17. Hartling, L.; Pickett, W.; Brison, R.J. Non-tractor, agricultural machinery injuries in Ontario. Can. J. Public Health 1997, 88, 32-35. [PubMed]

18. DeRoo, L.A.; Rautiainen, R.H. A systematic review of farm safety interventions. Am. J. Prev. Med. 2000, 18, 51-62. [CrossRef]

19. Tebeaux, E. Improving tractor safety warnings: Readability is missing. J. Agric. Saf. Health 2010, 16, $181-205$. [CrossRef] [PubMed]

20. Tebeaux, E. Safety warnings in tractor operation manuals, 1920-1980: Manuals and warnings don't always work. J. Tech. Writ. Commun. 2010, 40, 3-28. [CrossRef]

21. Caffaro, F.; Mirisola, A.; Cavallo, E. Safety signs on agricultural machinery: Pictorials do not always successfully convey their messages to target users. Appl. Ergon. 2017, 58, 156-166. [CrossRef] [PubMed]

22. Caffaro, F.; Cavallo, E. Comprehension of safety pictograms affixed to agricultural machinery: A survey of users. J. Saf. Res. 2015, 55, 151-158. [CrossRef] [PubMed]

23. Rasmussen, K.; Carstensen, O.; Lauritsen, J.M. Incidence of unintentional injuries in farming based on one year of weekly registration in Danish farms. Am. J. Ind. Med. 2000, 38, 82-89. [CrossRef]

24. Poisson, P.; Chinniah, Y. Observation and analysis of 57 lockout procedures applied to machinery in 8 sawmills. Saf. Sci. 2015, 72, 160-171. [CrossRef]

25. Baker, W.; Day, L.; Stephan, K.; Voaklander, D.; Ozanne-smith, J.; Dosman, J.; Hagel, L. Making Farm Machinery Safer. Lessons from Injured Farmers; Publication Number 07/190; Rural Industries Research and Development Corp.: Canberra, Australia, 2008; p. 84.

26. Pelliccia, L. Il Nuovo Testo Unico Di Sicurezza Sul Lavoro (No. 81-2008), 4th ed.; Maggioli Editore: Santarcangelo di Romagna, Italy, 2008.

27. Fargnoli, M.; Laurendi, V.; Tronci, M. Design for safety in agricultural machinery. In Proceedings of the DESIGN 2010, Dubrovnik, Croatia, 17-20 May 2010.

28. Cavallo, E.; Ferrari, E.; Bollani, L.; Coccia, M. Attitudes and behaviour of adopters of technological innovations in agricultural tractors: A case study in Italian agricultural system. Agric. Syst. 2014, 130, 44-54. [CrossRef]

29. ISTAT-Italian National Statisitical Institute. Farm Structure Survey-Year 2013. 2015. Available online: https:/ / www.istat.it/it/archivio/167401 (accessed on 27 September 2017).

30. ISTAT-Italian National Statisitical Institute. Aziende con Superficie Totale Per Classe di Superficie Totale (Superficie in Ettari). Dettaglio Per Regione-Anno 2013. Available online: http://agri.istat.it/sag_is_ pdwout /jsp / dawinci.jsp?q=p1SPA0000010000012000\&an=2013\&ig=1\&ct=1121\&id=68A\%7C98A (accessed on 27 September 2017).

31. ISTAT-Italian National Statisitical Institute. Aziende Agricole e Risultati Economici Per Classi di Fatturato, Composizione Percentuale-Anno 2014. Available online: http:/ / agri.istat.it/sag_is_pdwout/ jsp/GerarchieTerr.jsp?id=99A\%7C46A\&ct=314\&an=2009 (accessed on 27 September 2017).

32. Bentley, T.A.; Parker, R.J.; Ashby, L.; Moore, D.J.; Tappin, D.C. The role of the New Zealand forest industry injury surveillance system in a strategic Ergonomics, Safety and Health Research Programme. Appl. Ergon. 2002, 33, 395-403. [CrossRef]

33. Melemez, K. Risk factor analysis of fatal forest harvesting accidents: A case study in Turkey. Saf. Sci. 2015, 79, 369-378. [CrossRef]

34. Laschi, A.; Marchi, E.; Foderi, C.; Neri, F. Identifying causes, dynamics and consequences of work accidents in forest operations in an alpine context. Saf. Sci. 2016, 89, 28-35. [CrossRef]

35. Lundqvist, P.; Gustafsson, B. Accidents and accident prevention in agriculture a review of selected studies. Int. J. Ind. Ergon. 1992, 10, 311-319. [CrossRef]

36. Heist, A.M.; Ziernicki, R.M.; Railsback, B.T. Analysis of the hazards of wood chipper accidents. In Proceedings of the ASME 2011 International Mechanical Engineering Congress and Exposition, Denver, CO, USA, 11-17 November 2011.

37. OSHA. Hazards of Wood Chippers. Safety and Health Information Bulletin. 2008. Available online: https://www.osha.gov/dts/shib/shib041608.html (accessed on 27 September 2017).

38. Lanning, D.N.; Dooley, J.H.; Lanning, C.J. Shear Processing of Wood Chips into Feedstock Particles. In Proceedings of the 2012 ASABE Annual International Meeting, Dallas, TX, USA, 29 July-1 August 2012.

39. Facello, A.; Cavallo, E.; Magagnotti, N.; Paletto, G.; Spinelli, R. The effect of chipper cut length on wood fuel processing performance. Fuel Process. Technol. 2013, 116, 228-233. [CrossRef] 
40. Karha, K. Industrial supply chains and production machinery of forest chips in Finland. Biomass Bioenergy 2010, 35, 3404-3413. [CrossRef]

41. Spinelli, R.; Cavallo, E.; Eliasson, L.; Facello, A. Comparing the efficency of drum and disc chippers. Silva Fenn. 2013, 47. [CrossRef]

42. Poje, A.; Spinelli, R.; Magagnotti, N.; Mihelic, M. Exposure to noise in wood chipping operations under the conditions of agro-forestry. Int. J. Ind. Ergon. 2015, 50, 151-157. [CrossRef]

43. Colantoni, A.; Mazzocchi, F.; Laurendi, V.; Grigolato, S.; Monarca, F.; Monarca, D.; Cecchini, M. Innovative Solution for Reducing the Run-Down Time of the Chipper Disc Using a Brake Clamp Device. Agriculture 2017, 7, 71. [CrossRef]

44. Al-bassit, L.; Tricot, N. Amelioration de la Securite de la Dechiqueteuse Forestiere Etude de Reconception; Irstea Report; IRSTEA: Antony Cedex, France, 2015.

45. OSHA. Accident Search Results. Available online: https://www.osha.gov/pls/imis/AccidentSearch.search? acc_keyword=\%22Chipper\%22\&keyword_list=on (accessed on 22 September 2017).

46. Cardillo, C.; Cimino, O.; Gabrieli, G.; Giampaolo, A. La Meccanizzazione Agricola in Italia: Aspetti Tecnici, Economici, Ambientali e Sociali; Report INEA; INEA: Roma, Italy, 2013.

47. European Union. Standards in Europe. Available online: http://europa.eu/youreurope/business/product/ standardisation-in-europe/index_en.htm (accessed on 5 November 2017).

48. Klembalska, A.; Fancello, G. Increasing the quality of agricultural machinery testing-A comparison between Italian and Polish experience. Manag. Prod. Eng. Rev. 2015, 6, 14-24. [CrossRef]

49. GSE. Rapporto Statistico Energia da Fonti Rinnovabili. 2015. Available online: http://www. gse.it/it/salastampa/GSE_Documenti/Rapporto\%20statistico\%20GSE\%20-\%202014.pdf (accessed on 21 September 2017).

50. Berry, R.S.Y. Collecting data by in-depth interviewing. In Proceeding of the British Educational Association Annual Conference; University of Sussex: Brighton, UK, 1999; pp. 1-10.

51. CEN/TC 144/WG. N 175 CEN144 8 Rev EN 13525 Note of the French public authority (ref N170).

52. Purschwitz, M.A. Personal Protective Equipment and Safety Engineering of Machinery. In Agricultural Medicine; Lessenger, J.E., Ed.; Springer: New York, NY, USA, 2006; pp. 53-69.

53. Cavallo, E.; Ferrari, E.; Coccia, M. Likely technological trajectories in agricultural tractors by analysing innovative attitudes of farmers. Int. J. Technol. Policy Manag. 2015, 15, 158. [CrossRef]

54. Mrugalska, B.; Kawecka-Endler, A. Machinery design for construction safety in practice. Lect. Notes Comput. Sci. 2011, 6767, 388-397. [CrossRef]

55. Julius, A.K.; Kane, B.; Bulzacchelli, M.T.; Ryan, H.D. P. Compliance with the ANSI Z133.1-2006 safety standard among arborists in New England. J. Saf. Res. 2014, 51, 65-72. [CrossRef] [PubMed]

56. Julius, A.K. Investigation of Compliance with the Ansi Z133.1-2006 Safety Standard in the New England Tree Care Industry. Master's Thesis, University of Massachusetts Amherst, Amherst, MA, USA, February 2014.

57. Lorencowicz, E.; Uziak, J. Repair Cost of Tractors and Agricultural Machines in Family Farms. Agric. Agric. Sci. Procedia 2015, 7, 152-157. [CrossRef]

58. Hagel, L.; Pahwa, P.; Dosman, J.A.; Pickett, W. Economic worry and the presence of safety hazards on farms. Accid. Anal. Prev. 2013, 53, 156-160. [CrossRef] [PubMed]

59. Caffaro, F.; Lundqvist, P.; Cremasco, M.M.; Nilsson, K.; Pinzke, S.; Cavallo, E. Machinery-related perceived risks and safety attitudes in senior Swedish farmers. J. Agromed. 2017. [CrossRef] [PubMed]

60. Myers, J.R. Factors Associated with the Prevalence of Non-ROPS Tractors on Farms in the U.S. J. Agric. Saf. Health 2010, 16, 267-280. [CrossRef]

61. Jenkins, P.L.; Sorensen, J.A.; Yoder, A.; Myers, M.; Murphy, D.; Cook, G.; Wright, F.; Bayes, B.; May, J.J. Prominent Barriers and Motivators to Installing ROPS: An Analysis of Survey Responses from Pennsylvania and Vermont. J. Agric. Saf. Health 2012, 18, 103-112. [CrossRef] [PubMed]

62. Solomon, C. Accidental injuries in agriculture in the UK. Occup. Med. 2002, 52, 461-466. [CrossRef]

63. Correa, I.M.; Moreira, C.A.; Filipini, S.R.; Mello, R.d.C.; Pontes, P.S. Assessment of agricultural power take-off (pto) drive shafts guards in field conditions. Appl. Res. Agrotechnol. 2016, 9, 71-77.

(C) 2017 by the authors. Licensee MDPI, Basel, Switzerland. This article is an open access article distributed under the terms and conditions of the Creative Commons Attribution (CC BY) license (http:/ / creativecommons.org/licenses/by/4.0/). 